\title{
Clinical significance of disseminated tumour cells in non-small cell lung cancer
}

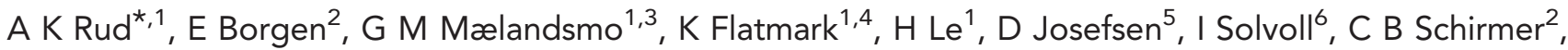
$\AA$ A Helland ${ }^{6,7,8}$, L Jørgensen ${ }^{9}, \mathrm{O}$ T Brustugun ${ }^{6,7,8}, \varnothing$ Fodstad $^{1}$ and K Boye ${ }^{1,7}$

${ }^{1}$ Department of Tumor Biology, Institute for Cancer Research, Oslo University Hospital, The Norwegian Radium Hospital, PO Box 4953 Nydalen NO-0424, Oslo, Norway; ${ }^{2}$ Department of Pathology, Oslo University Hospital, The Norwegian Radium Hospital, PO Box 4953 Nydalen NO-0424, Oslo, Norway; ${ }^{3}$ Department of Pharmacy, Faculty of Health Sciences, University of Tromsø 9037, Tromsø, Norway; ${ }^{4}$ Department of Surgical Oncology, Oslo University Hospital, The Norwegian Radium Hospital, PO Box 4953 Nydalen NO-0424, Oslo, Norway; ${ }^{5}$ Department of Cellular Therapy, Oslo University Hospital, The Norwegian Radium Hospital, PO Box 4953 Nydalen NO-0424, Oslo, Norway; ${ }^{6}$ Department of Genetics, Institute for Cancer Research, Oslo University Hospital, The Norwegian Radium Hospital, PO Box 4953 Nydalen NO-0424, Oslo, Norway; ${ }^{7}$ Department of Oncology, Oslo University Hospital, The Norwegian Radium Hospital, PO Box 4953 Nydalen NO-0424, Oslo, Norway; ${ }^{8}$ Faculty of Medicine, Institute of Clinical Medicine, University of Oslo, PO Box 1171 Blindern N-0318, Oslo, Norway and ${ }^{9}$ Department of Cardiovascular and Thoracic Surgery, Oslo University Hospital Rikshospitalet, PO Box 4953 Nydalen NO-0424, Oslo, Norway
\end{abstract}

Background: Early-stage non-small cell lung cancer (NSCLC) patients have a high risk of disease relapse despite curatively intended surgical resection, and the detection of tumour cells in the bone marrow could be one method of determining the presence of the disseminated disease in its early stages.

Methods: Bone marrow aspirates were collected from 296 patients at the time of surgery, and the presence of disseminated tumour cells was determined with the help of immunomagnetic selection (IMS) using the MOC31-antibody recognising EpCAM and with the help of standard immunocytochemistry (ICC) using the anti-cytokeratin (CK) antibodies AE1/AE3.

Results: Disseminated tumour cells were found in 152 of 252 (59\%) bone marrow samples using IMS and in 25 of 234 (11\%) samples using ICC. No association between the two detection methods was observed. The presence of EpCAM ${ }^{+}$cells was not associated with any clinicopathological parameters, whereas a higher frequency of $\mathrm{CK}^{+}$cells was found in patients with an advanced pT status. Disseminated tumour cells, as detected using IMS, had no prognostic impact. Patients with $\mathrm{CK}^{+}$cells in the bone marrow had a reduced relapse-free survival, but the difference was not statistically significant.

Conclusion: Our findings do not support the further development of DTC detection for clinical use in early-stage NSCLC. Future studies should include the molecular characterisation of DTCs, along with an attempt to identify subpopulations of cells with biological and clinical significance.

Lung cancer, of which non-small cell lung cancer (NSCLC) accounts for $85 \%$ of the cases, retains its position as one of the most commonly diagnosed cancer forms and the leading cause of cancer-related mortality (Jemal et al, 2011). Approximately 30\% of NSCLC patients present with early-stage disease, but relapse occurs in nearly half of these patients despite curatively intended surgical resection. One possible explanation could be that some patients diagnosed with localised NSCLC may have a more extensive disease, with a systemic dissemination of tumour cells that is not detectable using the standard clinical methods. Such cells

*Correspondence: Dr AK Rud; E-mail: ane.kongsgaard.rud@rr-research.no

Received 6 June 2013; revised 8 July 2013; accepted 10 July 2013; published online 13 August 2013

(c) 2013 Cancer Research UK. All rights reserved 0007-0920/13 
can be detected in the blood (circulating tumour cells, CTCs) or in the bone marrow (disseminated tumour cells, DTCs) (Pantel et al, 2008). The ability to detect early dissemination could potentially identify subgroups of early-stage patients with a high risk of disease relapse that could benefit from adjuvant therapy. A number of studies on various cancer types have reported an association between the presence of DTCs at the time of tumour resection and patient outcome (Pantel et al, 2008). Controversy exists, however, regarding the biological and clinical significance of DTCs, as only a small fraction of the tumour cells released into the circulation are able to form distant metastases (Fidler, 2003). Thus, some of the tumour cells detected in the bone marrow may be dormant and not necessarily of clinical importance (McGowan et al, 2009). In NSCLC, the currently available investigations on the prognostic value of DTCs have shown conflicting results (Cote et al, 1995; Pantel et al, 1996; Ohgami et al, 1997; Passlick et al, 1999; Hsu et al, 2000; Poncelet et al, 2001; Osaki et al, 2002; Sugio et al, 2002; Hsu et al, 2004; Brunsvig et al, 2008; Rusch et al, 2011). As of today, the detection of DTCs has no impact on NSCLC staging or treatment recommendations.

Several methods exist to identify tumour cells in the bone marrow of cancer patients. Immunocytochemistry (ICC), using antibodies against epithelial markers, has traditionally been the most common approach, followed by RT-PCR for the detection of tumour- and epithelial-cell-specific mRNA transcripts (Coello et al, 2004). The two antibodies most commonly used in ICC are $\mathrm{A} 45-\mathrm{B} / \mathrm{B} 3$, which has been reported to recognise cytokeratins (CK) 7, 8, 18 and 19 (Stigbrand et al, 1998; Effenberger et al, 2011), and AE1/AE3, which stains CKs 1-8, 10, 11, 13-16 and 19 (Coello et al, 2004). In our laboratory, we have developed an immunomagnetic selection (IMS) method, in which small magnetic particles coated with the antibody MOC31 are used to isolate tumour cells from the bone marrow. MOC31 recognises the EpCAM antigen, which is consistently expressed on the surface of most human epithelial cells (Flatmark et al, 2002), including most NSCLCs (Passlick et al, 2000; Went et al, 2006). The IMS method has previously been shown to provide a useful strategy for DTC detection in various cancer types, including lung cancer (Beiske et al, 1992; Flatmark et al, 2002; Faye et al, 2004; Bruland et al, 2005; Brunsvig et al, 2008; Flatmark et al, 2011). An advantage of the IMS method is that it allows rapid screening of as much as $2 \times 10^{7}$ cells, approximately ten-fold the number of cells usually analysed using ICC.

In this prospective study, we have investigated the presence of DTCs in the bone marrow collected from 296 patients with stages I-IIIA NSCLC undergoing curatively intended surgery, using both IMS and ICC. In addition, 81 bone marrow samples from healthy volunteers were investigated using IMS. We have compared the results from the two methods, investigated the associations with clinicopathological parameters and examined the prognostic impact of the presence of DTCs.

\section{MATERIALS AND METHODS}

Patients. Between December 2008 and August 2012, 296 patients with presumed or verified NSCLC who underwent curatively intended surgical resection at Rikshospitalet, Oslo University Hospital, Oslo, Norway were prospectively included in the study. Approval was received from the Regional Ethics Committee (S-06402b), and all the patients were informed and signed a written consent. The bone marrow was aspirated from the posterior iliac crest bilaterally under general anaesthesia at the time of primary surgery, prior to the surgical procedure. Forty patients were excluded from the study for the following reasons: histology other than NSCLC (benign histology (1), small-cell lung cancer (5), carcinoid (10) and lung metastases from other primary cancer types (4)), metastatic disease at the time of surgery (4), insufficient material for analysis (11) and bone marrow sampled at reoperation (5). The study population thus included 256 patients with histologically verified primary NSCLC. Resected tumour tissue was processed for routine histopathological assessment, and the histological subtypes were classified according to the WHO criteria. Tumours were staged according to the Union for International Cancer Control (UICC), TNM 7, and histopathological parameters were retrieved from the pathology reports. After surgery, patients were followed by clinical evaluation and radiological examination (CT or a conventional X-ray of the chest) in their respective local hospitals according to national guidelines. Follow-up data were obtained from the local hospitals and in some cases by contacting the patient's general practitioner. In addition, survival data were obtained from the National Registry of Norway and updated on 4 March 2013.

Immunomagnetic selection. The IMS was performed as described previously (Flatmark et al, 2002). In brief, Dynabeads M450 sheep anti-mouse (SAM) IgG1 (Dynal, Oslo, Norway) were coated with MOC31 antibody (batch no. 80.000, IQ products, Groningen, The Netherlands). Uncoated beads for control experiments were prepared in the same manner, without adding the MOC31 antibody. MNCs were separated from the bone marrow using Lymphoprep gradient centrifugation (Nycomed/Axis-Shield, Oslo, Norway), washed and then resuspended in PBS with $1 \%$ human serum albumin (HSA). To 10 - $\mathrm{ml}$ test tubes, $2 \times 10^{7}$ MNCs were added, and magnetic immunobeads with or without MOC31 antibody were added at a ratio of one bead to two MNCs in a total volume of $1 \mathrm{ml}$. The samples were incubated under continuous rotation at $4{ }^{\circ} \mathrm{C}$ for $30 \mathrm{~min}$, then diluted in cold PBS with $1 \%$ HSA and exposed to a strong magnet for 1-2 min to separate bound and unbound cells. The supernatant containing the unbound cells was removed, and the positive fraction was resuspended in PBS with 1\% HSA. Fractions of $20 \mu \mathrm{l}$ from the cell suspension were then examined using light microscope to identify and count the number of cells with membrane-bound beads. Cells were considered positive if they had bound a minimum of five beads to its surface and, evaluating the size and morphology, had diameters that exceeded the diameters of two beads (Figure 1). To determine the number of $\mathrm{EpCAM}^{+}$cells required to classify a bone marrow sample as positive, bone marrow samples from 81 healthy volunteers were investigated using the same method. Approximately $20 \mathrm{ml}$ of bone marrow was aspirated from the posterior iliac crest of the donors and processed and evaluated as described above.

Immunocytochemistry. Of the 256 collected BM samples, 238 samples had enough cells for the production of cytospins. Cytospins were prepared by centrifuging MNCs isolated from the bone marrow onto glass slides using a Hettich cytocentrifuge (Tutlingen, Germany). The slides were air-dried overnight and
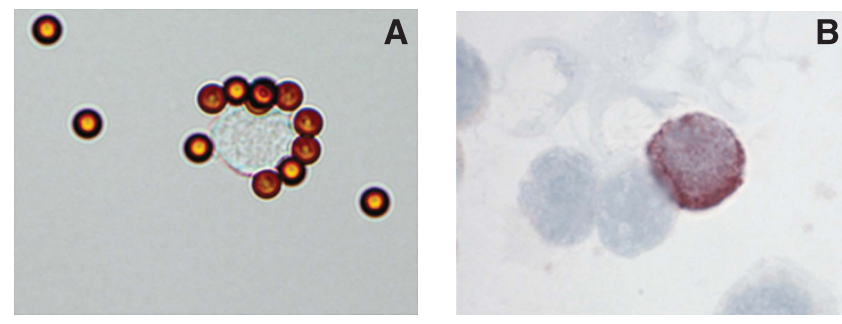

Figure 1. Representative photomicrographs of an $\mathrm{EpCAM}^{+}$cell as detected using IMS (A), and a $\mathrm{CK}^{+}$cell as detected using ICC (B). 
stored at $-70{ }^{\circ} \mathrm{C}$. ICC was performed by incubating four slides (500 000 cells per slide) with the anti-CK monoclonal antibodies AE1 and AE3 (Millipore, production numbers MAB 1612 and MAB 1611, Billerica, MA, USA). Four additional slides were incubated with a control antibody of the same immunoglobulin subtype (MOPC-21, IgG1, Sigma, prod. no. M9269, St Louis, MO, USA). The cytospins were screened using the Ariol SL50 automated screening system (now Leica Biosystems, Wetzlar, Germany) and reviewed by a dedicated technician. All possible positive candidate cells were closely evaluated by a pathologist and subjected to strict morphological classification according to standardised criteria as previously described (Borgen et al, 1999; Naume et al, 2004). A sample was scored as positive if no similar positive cells were detected in the corresponding negative control or if a higher number of positive cells were present in the AE1-/ AE3-stained slides than in the corresponding negative control slides. The presence of the same (or a lower) number of cells scored as tumour cells in the AE1-/AE3-stained slides as in the corresponding negative controls resulted in the exclusion of the sample (four cases).

Statistical analysis. Associations between the presence of DTCs and histopathological parameters were examined using a two-tailed Fisher's exact test or a linear-by-linear association $\chi^{2}$ test as appropriate. For analyses of associations between the number of DTCs detected using IMS and clinicopathological parameters, twosample $t$-test or one-way ANOVA test, as appropriate, was used. Survival was estimated according to the Kaplan-Meier method, and survival curves were compared using the log-rank test. Survival was measured from the date of surgery until the date of diagnosis of a recurrence or metastasis for relapse-free survival, and from the date of surgery until the death date for overall survival. All data analyses were performed using the SPSS statistical software version 18.0 (SPSS Inc., Chicago, IL, USA), and $P$-values $<0.05$ were considered statistically significant.

\section{RESULTS}

Patient characteristics and outcome. The clinicopathological parameters of the patient cohort are summarised in Table 1. There were $49 \%$ female and $51 \%$ male patients, and the mean age at the time of surgery was 67 years (range 39-87 years). One hundred and fifty-five patients $(60 \%)$ were in pTNM stage I, whereas 63 (25\%) patients were in pTNM II and 38 (15\%) were in pTNM III. For the follow-up and survival analysis, only patients who had undergone surgery before September 2011 were included, which resulted in a cohort of 183 patients with a median follow-up period of 23.4 months (range 6.2-50.4 months). Fifty-five of the 183 patients $(30 \%)$ developed local recurrence or metastasis, whereas 46 patients $(25 \%)$ died during the follow-up period.

Detection of $\mathrm{EpCAM}^{+}$cells in bone marrow from healthy donors. Among the 81 healthy bone marrow donors, there were 17 male and 64 female donors, and the mean age at the time of bone marrow aspiration was 37 years (range 20-63 years). MOC31-bead-bound $\left(\mathrm{EpCAM}^{+}\right.$) cells were found in 20 samples $(25 \%)$, with a median number of 6 rosetted cells (range $2-39$ ). One sample contained 39 rosetted cells, and the remaining varied between two and nine cells. Based on these findings, the cutoff value for a positive sample was set at 10 cells, which resulted in one positive donor bone marrow sample (1.2\%). Consequently, a patient sample was classified as positive if it contained a minimum of $11 \mathrm{EpCAM}^{+}$cells, and no positive cells were observed in the corresponding SAM IgG-bead control.

Detection of DTCs in patient samples and associations with clinicopathological parameters. Using the IMS method, four
Table 1. Demographics of patient cohort $(n=256)$

Patients

\begin{tabular}{|l|c|c|}
\hline Parameter & Number & Percent \\
\hline Sex & 131 & 51 \\
\hline Male & 125 & 49 \\
Female &
\end{tabular}

Age at surgery

\begin{tabular}{|l|l|l}
\hline$<65$ Years & 105 & 41 \\
$>65$ Years & 151 & 59
\end{tabular}

$>65$ Years

151

59

\section{Histology}

\begin{tabular}{|l|r|r}
\hline Adenocarcinoma & 161 & 63 \\
Squamous cell carcinoma & 82 & 32 \\
Large cell carcinoma & 13 & 5
\end{tabular}

\section{UICC stage/pTNM7}

\begin{tabular}{|l|r|r}
\hline I & 155 & 60 \\
II & 63 & 25 \\
III & 38 & 15
\end{tabular}

III

pT

PT1

PT2

PT3

pT4

$\mathrm{pN}$

pNO

pN1

pN2

38

25

15

Tumour size $(\mathrm{cm})$

\begin{tabular}{|l|r|r|}
\hline$<2.0 \mathrm{~cm}$ & 72 & 28 \\
$2.1-3.0 \mathrm{~cm}$ & 66 & 26 \\
$3.1-5.0 \mathrm{~cm}$ & 76 & 30 \\
$5.1-7.0 \mathrm{~cm}$ & 28 & 11 \\
$>7.0 \mathrm{~cm}$ & 14 & 5 \\
\hline
\end{tabular}

Tobacco use

Current smoker

Former smoker

Never smoker

Missing

90

90
152

13

DTCs detected by IMS $^{\mathrm{a}}$

\begin{tabular}{|l|l|l}
\hline EpCAM positive & 150 & 59 \\
EpCAM negative & 102 & 41 \\
\hline
\end{tabular}

DTCs detected by ICC ${ }^{b}$

\begin{tabular}{|l|r|r}
\hline Cytokeratin positive & 25 & 11 \\
Cytokeratin negative & 209 & 89
\end{tabular}

Abbreviations: $\quad$ DTC $=$ disseminated tumour cells; $\quad I C C=$ immunocytochemistry UICC $=$ Union for International Cancer Control.

$a_{n=252}$ because of rosetted cells in negative control in four cases.

$\mathbf{b}_{n=234}$ because of missing or non-evaluable cytospins in 22 cases.

samples were excluded from the analyses because of the presence of IgG-bead-binding cells in the negative control, resulting in a total of 252 samples available for analysis. In 150 samples (59\%), > 10 
$\mathrm{EpCAM}^{+}$cells were detected, and the median number of cells in the positive samples was 38 (a range of 11-200). Eleven to fifty $\mathrm{EpCAM}^{+}$cells were detected in $68 \%$ of the positive samples, whereas 51-100 $\mathrm{EpCAM}^{+}$cells were detected in 25\% and more than 100 positive cells were detected in $7 \%$ of the samples. Associations between the presence of DTCs and clinicopathological parameters are summarised in Table 2. As assessed using the IMS method, there was an even distribution of positive samples among the histological subgroups, with 91 out of 160 positive samples (57\%) in the adenocarcinoma patients, 52 out of $79(66 \%)$ positive samples in the squamous cell carcinoma patients and 7 out of 13 (54\%) positive samples in the large-cell carcinoma patients. The presence of $\mathrm{EpCAM}^{+}$cells did not differ according to the disease stage, as 90 out of $155(58 \%)$ of the stage-I patients were positive and 60 out of 97 (62\%) of pTNM stages II-III patients were positive. The presence of DTCs, detected using IMS, was not associated with any of the following clinicopathological parameters: pT, pN, tumour size, sex, age at surgery or tobaccosmoking habits (Table 2). Dividing the patients with positive samples into groups according to the number of $\mathrm{EpCAM}^{+}$cells, categorised as above, did not reveal any association with clinicopathological parameters. When analysing results using the ICC method, four samples were excluded from the analyses because of the presence of the same or a lower number of cells scored as tumour cells in the AE1/AE3 slides compared with the corresponding negative controls, resulting in a total of 234 evaluable patient samples. $\mathrm{CK}^{+}$cells were detected in 25 of these samples (11\%), and of these, 15 patients had one $\mathrm{CK}^{+}$cell; three patients had two $\mathrm{CK}^{+}$cells; four patients had three positive cells; one had four positive cells; one had five positive cells and one had 10 positive cells. A higher percentage of $\mathrm{CK}^{+}$samples was found in patients who were at a more advanced $\mathrm{pT}$ stage; however, the difference was not statistically significant (Table 2). An association between squamous cell histology and positive ICC was revealed: $18 \%(13 / 72)$ of the squamous cell carcinoma patients were $\mathrm{CK}^{+}$, compared with $7 \%$ (11 out of 150) of adenocarcinoma patients and $8 \%$ ( 1 out of 11$)$ of large-cell carcinoma patients $(P=0.05$, Table 2). The presence of DTCs detected using ICC was not associated with pTNM, pN status, sex, age at surgery or tobaccosmoking habits (Table 2). Of the 230 patient samples examined using both IMS and ICC, 14 patients were categorised as positive using both IMS and ICC, and there was no association between the results of the two detection methods.

Associations between clinicopathological parameters and patient outcome. The associations between clinicopathological parameters and the patient outcome are shown in Supplementary Table 1. Univariate analyses showed that the pTNM stage and the $\mathrm{pN}$ status were significantly associated with poor relapse-free survival ( $P=0.03$ and 0.003 , respectively, Supplementary Table 1$)$. Lymph node metastasis (pN1 or pN2 status) was the main contributor to the prognostic impact of the pTNM stage, whereas pT classification was not associated with poor outcome $(P=0.47)$. There was a significant association between the patient outcome and sex, with a 3 -year relapse-free survival rate of $49 \%$ for female patients, compared with $71 \%$ for male patients $(P=0.02$, Supplementary Table 1).

Associations between DTCs and patient outcome. The presence of $\mathrm{EpCAM}^{+}$cells as detected using IMS was not associated with relapse-free or overall survival when investigated using univariate Kaplan-Meier analyses $(P=0.59$ and 0.40 , respectively, Figure 2A and B). In fact, 33 out of $118(28 \%)$ of patients with $\mathrm{EpCAM}^{+}$ samples and 21 out of $62(35 \%)$ of the patients with EpCAM $^{-}$ samples developed disease relapse during the follow-up period. Furthermore, the exact number of $\mathrm{EpCAM}^{+}$cells detected was not associated with disease relapse ( $P=0.98$, Cox univariate analysis). Finally, survival analyses were also performed on patients divided
Table 2. Associations between the presence of DTC and clinicopathological parameters

\begin{tabular}{|l|c|c|c|c|c|c|}
\hline \multicolumn{3}{|c|}{ IMS $^{\text {a }}$ (n=252) } & \multicolumn{3}{c|}{ ICC $^{\text {a }}$ (n=234) } \\
\hline Parameter & $\boldsymbol{n}$ & $\%$ & P-value & $\boldsymbol{n}$ & $\%$ & P-value \\
\hline Sex & 80 & 62 & 0.37 & 15 & 13 & 0.33 \\
Female & 70 & 56 & & 10 & 9 & \\
\hline
\end{tabular}

Age at surgery

\begin{tabular}{|l|l|l|l|l|l|l|}
\hline$<65$ years & 56 & 54 & 0.19 & 14 & 10 & 0.75 \\
$>65$ years & 94 & 63 & & 11 & 12 & \\
\hline
\end{tabular}

\section{Histology}

Adenocarcinoma

Squamous cell carcinom

Large cell carcinoma

\begin{tabular}{|c|c|c|c|c|c|}
\hline 91 & 57 & 0.37 & 11 & 7 & 0.05 \\
52 & 66 & & 13 & 18 & \\
7 & 54 & & 1 & 8 & \\
\hline
\end{tabular}

UICC stage/pTNM7

\begin{tabular}{|l|c|c|c|c|c|c|}
\hline II II & 90 & 58 & 0.73 & 12 & 9 & 0.39 \\
III & 38 & 63 & & 9 & 15 & \\
\hline
\end{tabular}

pT

\begin{tabular}{|l|c|c|c|c|c|c|}
\hline pT1 & 54 & 59 & 0.68 & 6 & 7 & 0.07 \\
pT2 & 73 & 61 & & 12 & 12 & \\
pT3 & 20 & 57 & & 6 & 17 & \\
pT4 & 3 & 43 & & 1 & 17 & \\
\hline pN & 107 & 57 & 0.17 & 17 & 10 & 0.61 \\
\hline pN0 & 31 & 69 & & 6 & 14 & \\
pN1 & 12 & 67 & & 2 & 11 & \\
pN2 &
\end{tabular}

Tumour size $(\mathrm{cm})$

\begin{tabular}{|l|l|l|l|l|c|c|}
\hline$\leqslant 30 \mathrm{~cm}$ & 80 & 59 & 0.89 & 12 & 9 & 0.39 \\
$\geqslant 3.1 \mathrm{~cm}$ & 70 & 60 & & 13 & 13 & \\
\hline
\end{tabular}

\section{Tobacco use}

\begin{tabular}{|l|c|c|c|c|c|c|}
\hline Current smoker & 56 & 63 & 0.61 & 10 & 12 & 0.52 \\
Former smoker & 85 & 57 & & 14 & 10 & \\
Never smoker & 8 & 67 & & 0 & 0 & \\
\hline
\end{tabular}

Abbreviations: $\quad$ DTC $=$ disseminated tumour cells; $\quad I C C=$ immunocytochemistry; IMS = immunomagnetic selection; UICC = Union for International Cancer Control.

${ }^{\text {a }}$ Positive samples according to each method are shown.

into subgroups according to the number of IMS-positive cells without revealing any associations with the outcome. For DTCs detected using ICC, there was a small, nonsignificant difference in relapse-free survival between patients with $\mathrm{CK}^{-}$and $\mathrm{CK}^{+}$bone marrow samples $(P=0.26$, Figure $2 \mathrm{C})$. There was no association with overall survival $(P=0.98$, Figure $2 \mathrm{D})$. Forty-one percent (7 out of 17) of patients with $\mathrm{CK}^{+}$cells in the bone marrow developed disease relapse during the follow-up period, compared with $28 \%$ (41 out of 148) of the patients with negative bone marrow sample developing disease relapse. A small difference in survival rates was found, as the 3-year relapse-free survival for ICC-negative patients was $64 \%$, compared with $43 \%$ for ICCpositive patients. Subgroup survival analyses showed a prognostic impact of $\mathrm{CK}^{+}$cells in male patients $(P=0.05$, data not shown) and in patients $<65$ years old ( $P=0.03$, data not shown); however, caution should be taken when interpreting these results on account of the small number of patients in each group. 

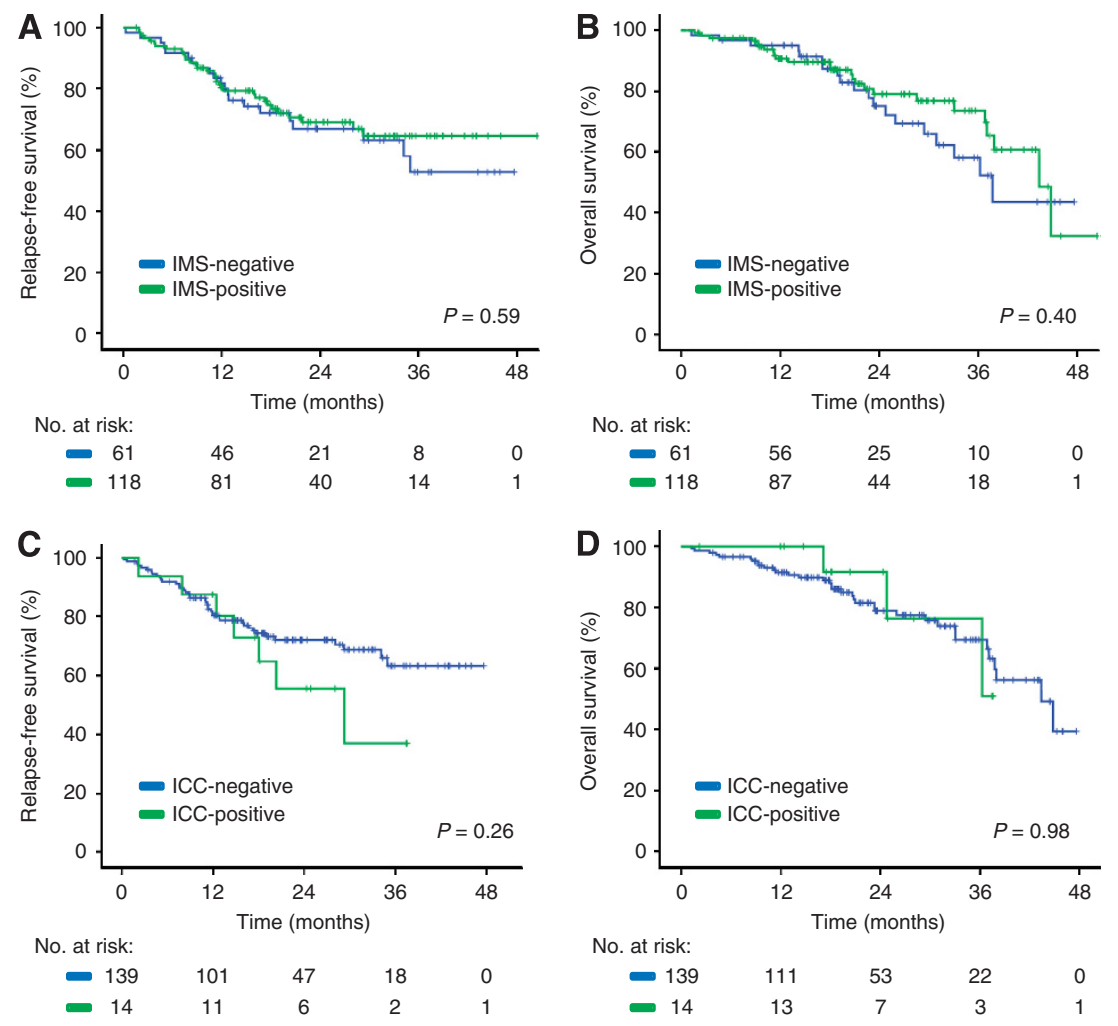

Figure 2. Kaplan-Meier survival plots depicting relapse-free survival and overall survival based on the presence of DTCs as detected using IMS (A, B) and ICC (C, D).

\section{DISCUSSION}

In this study, we have investigated the presence and prognostic significance of DTCs in prospectively collected bone marrow samples from surgically resected NSCLC patients using two different methods: IMS and ICC. We found no association between the EpCAM ${ }^{+}$cells detected with the MOC31 antibody using IMS and patient outcome in the present patient cohort. The presence of $\mathrm{CK}^{+}$cells detected with the AE1/AE3 antibodies using ICC was associated with a reduced relapse-free survival in certain subgroups of patients, but there was no significant prognostic impact on the patient cohort as a whole. To our knowledge, this is the first study investigating two different methods of DTC detection in a relatively large NSCLC patient cohort.

The clinical relevance of DTCs has been demonstrated in several studies in many types of cancer (Lin et al, 2011). Although previous investigations in lung cancer have shown somewhat contradictory results (Coello et al, 2004; Riethdorf et al, 2008; Balic et al, 2010), several studies have not been able to demonstrate an association between DTC detection and patient outcome (Hsu et al, 2000; Poncelet et al, 2001; Osaki et al, 2002; Hsu et al, 2004; Brunsvig et al, 2008; Rusch et al, 2011). Two of the latter studies included relatively large cohorts of early-stage NSCLC patients, with 212 and 115 patients, respectively; both performed ICC using anti-CK antibodies (Osaki et al, 2002; Hsu et al, 2004). Furthermore, the largest study by Rusch et al (2011), which analysed rib bone marrow from 821 patients with operable NSCLC using ICC with anti-CK antibodies, concluded that the presence of DTCs was not associated with reduced survival. Thus, based on the existing literature and our own results, we believe that no conclusive evidence exists to support the further development of DTC detection for clinical use in NSCLC.
As the presence of tumour cells in the bone marrow does not seem to reflect the outcome of lung cancer patients, one might speculate that the bone marrow is a less important microenvironment for metastatic spread in lung cancer than in other cancer types. Data indicate that the majority of DTCs and CTCs detected in the bone marrow and blood are in a non-proliferative or dormant state, unable to initiate metastasis in distant organs (Pantel et al, 1993, 2009). This could explain the lack of prognostic relevance of DTCs detected in NSCLC patients. Interestingly, a recent study showed that an immunophenotypically defined population of CTCs, but not the bulk of EpCAM ${ }^{+}$CTCs, was associated with decreased survival in metastatic breast cancer patients (Baccelli et al, 2013). Indeed, the molecular characterisation of DTCs and CTCs is important and could potentially reveal subpopulations of cells with biological and clinical significance in NSCLC.

To establish a cutoff level for the number of $\mathrm{EpCAM}^{+}$cells present in a bone marrow sample, we first investigated samples donated by 81 healthy volunteers. Using a cutoff of 10 rosetted cells, a reasonable specificity (98.8\%) was achieved. Using this cutoff, $59 \%$ of the patient samples were classified as IMS-positive, which is higher than that in previous reports in NSCLC (Brunsvig et al, 2008) and other tumour types (Beiske et al, 1992; Flatmark et al, 2002; Faye et al, 2004; Bruland et al, 2005; Flatmark et al, 2011). Interestingly, MOC31-bead-bound cells were detected in $25 \%$ of the donor samples, demonstrating that all the cells detected using the IMS method are not tumour cells. However, as the numbers of IMS-positive cells in the patient samples were significantly higher than in the donor samples, a significant fraction of the detected cells is most likely tumour cells. The possibility that concomitant pulmonary infection or inflammation might influence the presence of epithelial $\left(\mathrm{EpCAM}^{+}\right)$cells in the circulation and bone marrow should also be considered. In this study, the healthy donors constitute a different population from 
that of the patients in terms of age and gender distributions, whereas using COPD patients as a control group perhaps would have been more optimal. On the other hand, no association between the patients' tobacco-smoking habits and the presence of DTCs was found. Still, we cannot exclude the possibility that some of the detected cells constitute a non-malignant $\mathrm{EpCAM}^{+}$cell population that increases with the development of NSCLC. In a previously published report, we found MOC31-bead-bound cells in only one out of the 176 patients with malignant melanoma (Flatmark et al, 2002). The notable disparity in detected cells between this cohort and the healthy bone marrow donors in the present cohort further suggests the existence of a non-malignant EpCAM $^{+}$cell population that is influenced by systemic conditions, such as malignant disease. One can only speculate on the type and origin of these cells, but subpopulations of haematopoietic cells are known to express epithelial markers (Balic et al, 2010). In fact, plasma cells have been found to express EpCAM (Bergsagel et al, 1992; Armstrong and Eck, 2003), and weak binding of MOC31 to lymphocytes has been reported (Myklebust et al, 1991).

The detection rate of $11 \% \mathrm{CK}^{+}$cells using ICC is lower than reported in most previous studies on NSCLC. Except in the large cohort presented by Rusch et al (2011), where $\mathrm{CK}^{+}$cells were detected in only $8 \%$ of bone marrow samples (Rusch et al, 2011), the frequency in NSCLC patients has ranged from 22 to $60 \%$ (Cote et al, 1995; Pantel et al, 1996; Ohgami et al, 1997; Passlick et al, 1999; Hsu et al, 2000; Poncelet et al, 2001; Osaki et al, 2002; Sugio et al, 2002; Yasumoto et al, 2003). One reason for this difference may be the favourable characteristics of the investigated patient cohort, as $60 \%$ of patients were in stage I and $74 \%$ were pN0. Furthermore, a standardised and careful cell evaluation was performed in our study to avoid scoring false-positive haematopoietic cells as tumour cells. Several of the previous studies that have reported a higher number of $\mathrm{CK}^{+}$cells have used less strict criteria for DTC positivity (Osaki et al, 2002; Yasumoto et al, 2003; Hsu et al, 2004). In contrast to the cells detected using IMS, the ICC-positive cells we have detected are in all likelihood tumour cells, as this method allows for morphological classification of the positive cells according to standardised criteria, and numerous previous studies using $\mathrm{CK}$ as an epithelial-cell marker have been published.

We observed a low degree of overlap between the detection methods, an observation that is in accordance with a previous study comparing IMS with ICC in colorectal cancer (Flatmark et al, 2011), as well as with a comparison between two different anti-CK antibodies in breast cancer (Effenberger et al, 2011). These findings suggest that different subpopulations of tumour cells with distinct molecular characteristics and biological properties are detected using the different antibodies. Moreover, CK expression may vary in tumour cells during disease progression (Woelfle et al, 2004; Willipinski-Stapelfeldt et al, 2005), and individual CKs can be downregulated as a consequence of an epithelial-mesenchymal transition (Mani et al, 2008). The frequency and number of DTCs detected may also be influenced by other factors, such as the time of bone marrow aspiration (before versus after the surgical procedure), the site and volume of aspiration (iliac crest versus costa or sternum), the number of cells examined, the antibodies used and the criteria for positivity.

Nearly half of NSCLC patients undergoing curatively intended surgical resection experience disease relapse, suggesting that systemic dissemination of tumour cells may occur early during tumour development in NSCLC patients, and the detection of disseminated disease in these patients could have a large clinical impact. Our data show that the presence of IMS-positive cells was not associated with the outcome, whereas a weak association with advanced tumour stage and poor prognosis was found for the ICCpositive patients. Taken together, the present results do not support the further development of DTC detection for clinical use in early stage NSCLC. In our opinion, future studies should incorporate molecular characterisation of DTCs, aiming to identify subpopulations of cells with biological and clinical significance.

\section{ACKNOWLEDGEMENTS}

We would like to thank Hanne Kleppe Høifødt, Ildri Haltbakk, Siri Juell, Heidi Rasmussen, Frazia Fida, Indrejit Dybsjord and the staff at The Micrometastasis Laboratory, Department of Pathology, The Norwegian Radium Hospital, for excellent technical assistance. This work was supported by the Research Council of Norway (grant no. 191431/V50 to AKR) and the Norwegian Cancer Society (grant no. 421852 to GMM and grant no. 42000063406 to ØF).

\section{CONFLICT OF INTEREST}

The authors declare no conflict of interest.

\section{REFERENCES}

Armstrong A, Eck SL (2003) EpCAM: A new therapeutic target for an old cancer antigen. Cancer Biol Ther 2: 320-326.

Baccelli I, Schneeweiss A, Riethdorf S, Stenzinger A, Schillert A, Vogel V, Klein C, Saini M, Bauerle T, Wallwiener M, Holland-Letz T, Hofner T, Sprick M, Scharpff M, Marme F, Sinn HP, Pantel K, Weichert W, Trumpp A (2013) Identification of a population of blood circulating tumor cells from breast cancer patients that initiates metastasis in a xenograft assay. Nat Biotechnol 31: 539-544.

Balic M, Williams A, Dandachi N, Cote RJ (2010) Micrometastasis: detection methods and clinical importance. Cancer Biomark 9: 397-419.

Beiske K, Myklebust AT, Aamdal S, Langholm R, Jakobsen E, Fodstad O (1992) Detection of bone marrow metastases in small cell lung cancer patients. Comparison of immunologic and morphologic methods. Am J Pathol 141: 531-538.

Bergsagel PL, Victor-Kobrin C, Timblin CR, Trepel J, Kuehl WM (1992) A murine cDNA encodes a pan-epithelial glycoprotein that is also expressed on plasma cells. J Immunol 148: 590-596.

Borgen E, Naume B, Nesland JM, Kvalheim G, Beiske K, Fodstad O, Diel I, Solomayer EF, Theocharous P, Coombes RC, Smith BM, Wunder E, Marolleau JP, Garcia J, Pantel K (1999) Standardization of the immunocytochemical detection of cancer cells in BM and blood: I. establishment of objective criteria for the evaluation of immunostained cells. Cytotherapy 1: 377-388.

Bruland OS, Hoifodt H, Saeter G, Smeland S, Fodstad O (2005) Hematogenous micrometastases in osteosarcoma patients. Clin Cancer Res 11: 4666-4673.

Brunsvig PF, Flatmark K, Aamdal S, Hoifodt H, Le H, Jakobsen E, Sandstad B, Fodstad O (2008) Bone marrow micrometastases in advanced stage non-small cell lung carcinoma patients. Lung cancer (Amsterdam, Netherlands) 61: 170-176.

Coello MC, Luketich JD, Litle VR, Godfrey TE (2004) Prognostic significance of micrometastasis in non-small-cell lung cancer. Clin Lung Cancer 5: 214-225.

Cote RJ, Beattie EJ, Chaiwun B, Shi SR, Harvey J, Chen SC, Sherrod AE, Groshen S, Taylor CR (1995) Detection of occult bone marrow micrometastases in patients with operable lung carcinoma. Ann Surg 222: 415-423, Discussion 423-5.

Effenberger KE, Borgen E, Eulenburg CZ, Bartkowiak K, Grosser A, Synnestvedt M, Kaaresen R, Brandt B, Nesland JM, Pantel K, Naume B (2011) Detection and clinical relevance of early disseminated breast cancer cells depend on their cytokeratin expression pattern. Breast Cancer Res Treat 125: 729-738.

Faye RS, Aamdal S, Hoifodt HK, Jacobsen E, Holstad L, Skovlund E, Fodstad O (2004) Immunomagnetic detection and clinical significance of micrometastatic tumor cells in malignant melanoma patients. Clin Cancer Res 10: 4134-4139.

Fidler IJ (2003) The pathogenesis of cancer metastasis: the 'seed and soil' hypothesis revisited. Nat Rev 3: 453-458. 
Flatmark K, Bjornland K, Johannessen HO, Hegstad E, Rosales R, Harklau L, Solhaug JH, Faye RS, Soreide O, Fodstad O (2002) Immunomagnetic detection of micrometastatic cells in bone marrow of colorectal cancer patients. Clin Cancer Res 8: 444-449.

Flatmark K, Borgen E, Nesland JM, Rasmussen H, Johannessen HO, Bukholm I, Rosales R, Harklau L, Jacobsen HJ, Sandstad B, Boye K, Fodstad O (2011) Disseminated tumour cells as a prognostic biomarker in colorectal cancer. Br J Cancer 104: 1434-1439.

Hsu CP, Shai SE, Hsia JY, Chen CY (2004) Clinical significance of bone marrow microinvolvement in nonsmall cell lung carcinoma. Cancer 100: 794-800.

Hsu CS, Chen CY, Kwang PC, Miao J, Hsia JY, Shai SE (2000) Bone-marrow microinvolvement in non-small cell lung cancer is not a reliable indicator of tumour recurrence and prognosis. Eur J Surg Oncol 26: 691-695.

Jemal A, Bray F, Center MM, Ferlay J, Ward E, Forman D (2011) Global cancer statistics. CA Cancer J Clin 61: 69-90.

Lin H, Balic M, Zheng S, Datar R, Cote RJ (2011) Disseminated and circulating tumor cells: role in effective cancer management. Crit Rev Oncol Hematol 77: 1-11.

Mani SA, Guo W, Liao MJ, Eaton EN, Ayyanan A, Zhou AY, Brooks M, Reinhard F, Zhang CC, Shipitsin M, Campbell LL, Polyak K, Brisken C, Yang J, Weinberg RA (2008) The epithelial-mesenchymal transition generates cells with properties of stem cells. Cell 133: 704-715.

McGowan PM, Kirstein JM, Chambers AF (2009) Micrometastatic disease and metastatic outgrowth: clinical issues and experimental approaches. Future Oncol 5: 1083-1098.

Myklebust AT, Beiske K, Pharo A, Davies CD, Aamdal S, Fodstad O (1991) Selection of anti-SCLC antibodies for diagnosis of bone marrow metastasis. Br J Cancer 14: 49-53.

Naume B, Wiedswang G, Borgen E, Kvalheim G, Karesen R, Qvist H, Janbu J, Harbitz T, Nesland JM (2004) The prognostic value of isolated tumor cells in bone marrow in breast cancer patients: evaluation of morphological categories and the number of clinically significant cells. Clin Cancer Res 10: 3091-3097.

Ohgami A, Mitsudomi T, Sugio K, Tsuda T, Oyama T, Nishida K, Osaki T, Yasumoto K (1997) Micrometastatic tumor cells in the bone marrow of patients with non-small cell lung cancer. Ann Thorac Surg 64: 363-367.

Osaki T, Oyama T, Gu CD, Yamashita T, So T, Takenoyama M, Sugio K, Yasumoto K (2002) Prognostic impact of micrometastatic tumor cells in the lymph nodes and bone marrow of patients with completely resected stage I non-small-cell lung cancer. J Clin Oncol 20: 2930-2936.

Pantel K, Alix-Panabieres C, Riethdorf S (2009) Cancer micrometastases. Nat Rev Clin Oncol 6: 339-351.

Pantel K, Brakenhoff RH, Brandt B (2008) Detection, clinical relevance and specific biological properties of disseminating tumour cells. Nat Rev 8: 329-340.

Pantel K, Izbicki J, Passlick B, Angstwurm M, Haussinger K, Thetter O, Riethmuller G (1996) Frequency and prognostic significance of isolated tumour cells in bone marrow of patients with non-small-cell lung cancer without overt metastases. Lancet 347: 649-653.

Pantel K, Schlimok G, Braun S, Kutter D, Lindemann F, Schaller G, Funke I, Izbicki JR, Riethmuller G (1993) Differential expression of proliferation-associated molecules in individual micrometastatic carcinoma cells. J Natl Cancer Inst 85: 1419-1424.

Passlick B, Kubuschok B, Izbicki JR, Thetter O, Pantel K (1999) Isolated tumor cells in bone marrow predict reduced survival in node-negative non-small cell lung cancer. Ann Thorac Surg 68: 2053-2058.

Passlick B, Sienel W, Seen-Hibler R, Wockel W, Thetter O, Pantel K (2000) The 17-1A antigen is expressed on primary, metastatic and disseminated non-small cell lung carcinoma cells. Int J Cancer 87: 548-552.

Poncelet AJ, Weynand B, Ferdin F, Robert AR, Noirhomme PH (2001) Bone marrow micrometastasis might not be a short-term predictor of survival in early stages non-small cell lung carcinoma. Eur J Cardiothorac Surg 20: 481-488.

Riethdorf S, Wikman H, Pantel K (2008) Review: biological relevance of disseminated tumor cells in cancer patients. Int J Cancer 123: 1991-2006.

Rusch VW, Hawes D, Decker PA, Martin SE, Abati A, Landreneau RJ, Patterson GA, Inculet RI, Jones DR, Malthaner RA, Cohen RG, Ballman K, Putnam Jr JB, Cote RJ (2011) Occult metastases in lymph nodes predict survival in resectable non-small-cell lung cancer: report of the ACOSOG Z0040 trial. J Clin Oncol 29: 4313-4319.

Stigbrand T, Andres C, Bellanger L, Bishr Omary M, Bodenmuller H, Bonfrer H, Brundell J, Einarsson R, Erlandsson A, Johansson A, Leca JF, Levi M, Meier T, Nap M, Nustad K, Seguin P, Sjodin A, Sundstrom B, van Dalen A, Wiebelhaus E, Wiklund B, Arlestig L, Hilgers J (1998) Epitope specificity of 30 monoclonal antibodies against cytokeratin antigens: the ISOBM TD5-1 Workshop. Tumour Biol 19: 132-152.

Sugio K, Kase S, Sakada T, Yamazaki K, Yamaguchi M, Ondo K, Yano T (2002) Micrometastasis in the bone marrow of patients with lung cancer associated with a reduced expression of E-cadherin and beta-catenin: risk assessment by immunohistochemistry. Surgery 131: S226-S231.

Went P, Vasei M, Bubendorf L, Terracciano L, Tornillo L, Riede U, Kononen J, Simon R, Sauter G, Baeuerle PA (2006) Frequent high-level expression of the immunotherapeutic target Ep-CAM in colon, stomach, prostate and lung cancers. Br J Cancer 94: 128-135.

Willipinski-Stapelfeldt B, Riethdorf S, Assmann V, Woelfle U, Rau T, Sauter G, Heukeshoven J, Pantel K (2005) Changes in cytoskeletal protein composition indicative of an epithelial-mesenchymal transition in human micrometastatic and primary breast carcinoma cells. Clin Cancer Res 11: 8006-8014.

Woelfle U, Sauter G, Santjer S, Brakenhoff R, Pantel K (2004) Down-regulated expression of cytokeratin 18 promotes progression of human breast cancer. Clin Cancer Res 10: 2670-2674.

Yasumoto K, Osaki T, Watanabe Y, Kato H, Yoshimura T (2003) Prognostic value of cytokeratin-positive cells in the bone marrow and lymph nodes of patients with resected nonsmall cell lung cancer: a multicenter prospective study. Ann Thorac Surg 76: 194-201, Discussion 202.

This work is published under the standard license to publish agreement. After 12 months the work will become freely available and the license terms will switch to a Creative Commons AttributionNonCommercial-Share Alike 3.0 Unported License.

Supplementary Information accompanies this paper on British Journal of Cancer website (http://www.nature.com/bjc) 